\title{
Bulbar dysfunction in normal pressure hydrocephalus: a prospective study
}

\author{
Ekawut Chankaew, MD,, Prajak Srirabheebhat, MD, ${ }^{1}$ Sriwimon Manochiopinig, PhD, ${ }^{2}$ \\ Theerapol Witthiwej, MD, ${ }^{1}$ and Itsara Benjamin, MD \\ 1Division of Neurosurgery, Department of Surgery, and 'Division of Speech-Language Therapy, Department of Rehabilitation \\ Medicine, Faculty of Medicine Siriraj Hospital, Mahidol University, Bangkok, Thailand
}

\begin{abstract}
OBJECTIVE Normal pressure hydrocephalus (NPH) is clinically characterized by gait disturbance, cognitive impairment, and urinary incontinence, as well as enlargement of the ventricles. To the best of the authors' knowledge, there have been no previous publications regarding the correlation between bulbar dysfunction and NPH. The primary objective of this study was to compare preoperative and postoperative prevalence of bulbar dysfunction in patients with NPH. Secondary objectives included assessing the results of surgery for swallowing, speech, gait, cognition, and urination, and evaluating the correlation between bulbar dysfunction and triad symptoms.
\end{abstract}

METHODS Fifty-three patients with NPH who underwent shunt placement surgery at Siriraj Hospital were included in the study. Patients were evaluated for gait, cognition, urination, swallowing, and speech before and 6 months after shunt placement. Triad symptoms were assessed using standard methods. Bulbar dysfunctions were assessed using the Swallowing Problem Questionnaire, Thai Articulation Test, Resonation Screening Test (RST), and Thai Nasality Test. The Thai Speech Assessment Program and nasometer were used for objective speech measurement.

RESULTS Preoperatively, 86\% (43/50) of patients had swallowing problems and 75\% (37/49) had speech problems, as measured by the RST. Postoperatively, there was significant improvement in swallowing $(p<0.001)$, speech problems by RST ( $p=0.008)$, and voice volume $(p=0.009)$, but no significant change in the nasometer test. All triad symptoms were improved. There were significant correlations between swallowing impairment and gait disturbance $(r=0.358, p=$ $0.009)$, and RST and cognitive impairment ( $r=-0.502, p<0.001)$.

CONCLUSIONS This is the first study of bulbar dysfunction in patients with NPH. The results showed that the prevalence of bulbar dysfunction is very high. The correlation between bulbar dysfunction and the classic NPH triad has been documented and published. These bulbar symptoms also significantly improved after surgery. As such, bulbar dysfunction should be regarded as a core symptom that should be considered along with the classic triad in the clinical diagnosis and management of NPH.

http://thejns.org/doi/abs/10.3171/2016.6.FOCUS16183

KEY WORDS normal pressure hydrocephalus; bulbar dysfunction; speech; swallowing; voice; resonance

$\mathrm{N}$ ORMAL pressure hydrocephalus (NPH) is a syndrome characterized by gait disturbance, cognitive impairment, and urinary incontinence, as well as enlargement of the ventricles, which results from disturbance of CSF circulation in a setting of normal CSF pressure. ${ }^{8,16,17,28,30,33,47} \mathrm{NPH}$ has been categorized into idio- pathic and secondary forms. Secondary NPH occurs after trauma, subarachnoid hemorrhage, meningitis, or intracranial surgery, and the idiopathic form is characterized by no known causative disorders. ${ }^{28,33}$

The pathogenesis of NPH remains uncertain, although several hypotheses have been proposed. Suggested mecha-

ABBREVIATIONS CBF = cerebral blood flow; CBT = corticobulbar tract; CST = corticospinal tract; LPS = lumboperitoneal shunt; ICH = intracranial hematoma; IQR = interquartile range; $\mathrm{NPH}=$ normal pressure hydrocephalus; $\mathrm{PVWM}=$ periventricular white matter; $r_{\mathrm{p}}=$ point-biserial correlation coefficient; $r_{\mathrm{s}}=$ Spearman's rank correlation coefficient; RST = Resonation Screening Test; SPQ = Swallowing Problem Questionnaire; TAT = Thai Articulation Test; TMSE = Thai Mental State Examination; VPI = velopharyngeal inadequacy; VPS = ventriculoperitoneal shunt.

SUBMITTED April 27, 2016. ACCEPTED June 14, 2016.

INCLUDE WHEN CITING DOI: 10.3171/2016.6.FOCUS16183. 
nisms responsible for the associated clinical symptoms include reduction in blood flow and metabolism, and altered neuronal conduction due to stretching of periventricular white matter (PVWM). ${ }^{4,12,14,28,29,33,45}$ In 1965, Adams et al. ${ }^{2}$ proposed a triad of symptoms for NPH, consisting of gait disturbance, cognitive impairment, and urinary incontinence. Many other symptoms have been reported, including subsequent apathy, anxiety, depression, ${ }^{34,39,43}$ impaired wakefulness, ${ }^{7,24}$ and sexual dysfunction, ${ }^{31}$ but on our review of the literature, no previous studies have investigated and reported on bulbar dysfunction in NPH.

We observed that several patients with a history of frequent choking had been admitted to the intensive care unit because of aspiration pneumonia before a diagnosis of NPH was made. Soon after shunt placement surgery, these patients had no further episodes of aspiration or choking. Moreover, these patients experienced hoarseness or hypophonia, which is usually concomitant with some degree of aspiration. The cessation or reduction in severity of aspiration also occurs after the CSF tap test. These symptoms may be explained by a stretching of PVWM. An enlarged ventricle can affect corticospinal integrity, thereby causing gait disturbance in a patient with NPH. ${ }^{6,14,15,40}$ The corticobulbar tract may also be distorted or otherwise affected by the enlarged ventricle, resulting in bulbar dysfunction.

The primary objective of this study was to compare preoperative and postoperative prevalence of bulbar dysfunction in patients with NPH. Secondary objectives included assessing the results of surgery for swallowing, speech, gait, cognition, and urination, and evaluating the correlation between bulbar dysfunction and triad symptoms.

\section{Methods \\ Study Design}

This prospective study was conducted at the Division of Neurosurgery, Department of Surgery, Faculty of Medicine Siriraj Hospital, Mahidol University, during the study period from March 2013 to March 2015. The study protocol was approved by the Siriraj Institutional Review Board and written informed consent was obtained from all patients or their guardian/representative, when applicable.

\section{Study Population}

Candidates for our study were patients with probable $\mathrm{NPH}$. The following inclusion and exclusion criteria were adopted. The inclusion criteria (all required) were as follows: 1) patients with more than 1 of the following symptoms: gait disturbance, cognitive impairment, and urinary incontinence; 2) patients with clinical symptoms that could not be completely explained by other diseases; 3 ) patients with ventricular dilation documented by $\mathrm{CT}$ or MRI; and 4) patients with CSF pressure lower than $20 \mathrm{~cm}$ $\mathrm{H}_{2} \mathrm{O}$ with normal CSF cell count. The exclusion criteria (at least 1 required) were: 1) patients with diseases or medical conditions of the head and neck region that could cause swallowing and speech problems (e.g., tumor, achalasia, esophageal spasm, reflux laryngitis, tracheostomy); 2) pa- tients with neurological lesions that caused bulbar palsy; or 3) patients who were unable to speak.

\section{Shunt Placement Procedures}

Patients who met all of the above inclusion criteria were enrolled. Enrolled participants then underwent shunt placement surgery with a ventriculoperitoneal shunt (VPS) or lumboperitoneal shunt (LPS), depending upon surgeon and patient preference. Enrolled participants were evaluated before shunting and at 1,3, and 6 months after surgery.

VPS placement was performed under general anesthesia using a programmable Codman Hakim Programmable Valve (Codman \& Shurtleff, Inc.), Medtronic Strata II valve (Medtronic), or medium-pressure Medtronic valve (Medtronic), according to surgeon and patient preference. LPS placement was performed under general anesthesia using the programmable Medtronic Strata NSC valve (Medtronic). The initial pressure for the shunt system was set after surgery. Valve pressure was readjusted at postoperative intervals, as required. Shunt function was assessed regularly, especially when there was no improvement in clinical symptoms.

\section{Outcome Measurements}

The outcome measurements included: the number of steps and time (seconds) needed to walk $10 \mathrm{~m}$ at free speed; the Thai Mental State Examination (TMSE); ${ }^{48}$ and an ordinal urinary incontinence scale, ${ }^{8}$ in which the level of incontinence ranged from 1 to 6 , with a higher score indicating a more incontinent condition.

Bulbar dysfunction was categorized into swallowing problems and speech problems. A swallowing problem was evaluated using the Swallowing Problem Questionnaire (SPQ) and a speech problem was evaluated using an articulation test, the volume and frequency of the voice, and resonance.

\section{Swallowing Problem Questionnaire}

Designed by Manochiopinig et al., the SPQ consists of 16 swallowing-related questions that relate to swallowing disorders, such as choking, hoarseness, wet/gurgly voice, dysphagia, spilling of food from the mouth, extra time needed to chew, and reduced eating (Table 1). ${ }^{23}$ Each question represents 1 swallowing problem. All questions have 2 possible answers: the presence or absence of that swallowing-related symptom (symptom presence $=1$, symptom absence $=0$ points). The maximum score is 16 , with a score of 0 indicating normal swallowing function. The patient or a relative was interviewed by a physician to facilitate the completion of the SPQ.

\section{Speech Assessment}

All patients were evaluated by a professional speechlanguage pathologist. The assessment consisted of $3 \mathrm{com}-$ ponent parts.

Articulation Test. Patients were tested using the Thai Articulation Test (TAT), ${ }^{26,27}$, which consists of all Thai phonemes, including 21 initial consonants, 8 final consonants, 12 clusters, 24 vowels, and 5 tones in the Thai 
TABLE 1. Swallowing Problem Questionnaire

\begin{tabular}{lcc}
\hline \multicolumn{1}{c}{ Question } & Yes & No \\
\hline 1. Difficulty swallowing & $\square$ & $\square$ \\
\hline 2. Food struck in the throat & $\square$ & $\square$ \\
\hline 3. Spill food from the mouth & $\square$ & $\square$ \\
\hline 4. Getting food stuck in cheek & $\square$ & $\square$ \\
\hline 5. Refuse to eat & $\square$ & $\square$ \\
\hline 6. Extra time needed to chew & $\square$ & $\square$ \\
\hline 7. Smaller mouthful & $\square$ & $\square$ \\
\hline 8. Eat less & $\square$ & $\square$ \\
\hline 9. Choking & $\square$ & $\square$ \\
\hline 10. Chronic cough & $\square$ & $\square$ \\
\hline 11. Aspiration pneumonia & $\square$ & $\square$ \\
\hline 12. Admission due to swallowing disorders & $\square$ & $\square$ \\
\hline 13. Wet or gurgly voice & $\square$ & $\square$ \\
\hline 14. Hoarseness & $\square$ & $\square$ \\
\hline 15. Weight loss & $\square$ & $\square$ \\
\hline 16. Food textures require change (liquefying, & $\square$ & $\square$ \\
\hline chopping, pureeing, or nasogastric tube) & \\
\hline Total score & \\
\hline
\end{tabular}

language. Patients pronounce a list of words aloud until the test is completed and articulation is determined to be normal or abnormal.

Volume and Frequency of Voice. This component was assessed using the Thai Speech Assessment Program, a program developed by the National Electronics and Computer Technology Center, in Bangkok, Thailand. Using normal-conversation voice volume, patients count from 1 to 10 into a microphone that is connected to a computer. The software then computes and analyzes voice volume $(\mathrm{dB})$ and voice frequency $(\mathrm{Hz})$. The distance between the patient's mouth and the microphone was 6 inches. Patients performed this exercise 2 times, with the average of the 2 times recorded as the test result.

\section{Resonance Testing}

Resonance is the speech quality that results from sound vibrations in the pharynx, oral cavity, and nasal cavity. Normal resonance is highly dependent on normal velopharyngeal structures and function. Velopharyngeal structures include the velum, lateral pharyngeal walls, and posterior pharyngeal wall. For normal speech resonance, the velopharyngeal port should be completely closed during the production of oral sounds (all Thai consonants, except $/ \mathrm{m}, \mathrm{n}, \mathrm{ng} / \mathrm{phonemes}$ ), sound energy should be blocked, and speech sound should be projected out through the oral cavity. When the velopharyngeal port is open during the production of nasal sounds (/m, n, and ng/ phonemes), sound energy is relatively unimpeded through the pharynx and nasal cavity. $5,10,18,22,37$

Hypernasality is a resonance disorder that results from velopharyngeal inadequacy (VPI). Specifically, in patients with hypernasality, oral sounds inappropriately resonate into the nasal cavity due to inadequate closure of the velopharyngeal valve.
TABLE 2. Resonance Screening Test (RST)

\begin{tabular}{l}
\hline Result \\
\hline 1. Piti kub rod tuktuk pai ta lad pak kret seu pla kra bok pad \\
ki lo \\
Patient repeats the utterance 2 times, with and without \\
the nostrils occluded. The examiner listens for differ- \\
ences in the quality of speech production. If speech \\
quality does not change, this indicates that the patient \\
has normal speech. \\
\hline 2. Manee nung deum num ma now / Mhor young mai nud \\
wan nae non / Nang ngam reum tum ngan \\
Patient repeats the utterance 2 times, with and without \\
the nostrils occluded. The examiner listens for differ- \\
ences in the quality of speech production. If speech \\
quality changes, this indicates that the patient has \\
normal speech. \\
\hline 3. Baimai baemeu bubee \\
Patient produces the phonemes in a repetitive manner \\
for three cycles. The examiner listens for differences in \\
the quality of speech production. If speech quality does \\
not change, this indicates that the patient has normal \\
speech. \\
\hline 4. Patient closes his/her mouth and builds up intra-oral air \\
until cheeks are puffy and oral cavity is completely full \\
of air. \\
\hline 5. Patient makes puffy cheeks similar to the preceding test \\
(test 4), then protrudes his/her tongue. \\
For tests 4 and 5 above, the examiner should note whether \\
the patient was able to hold air in his/her mouth with or \\
without (audible) nasal air emission \\
Total score \\
\hline
\end{tabular}

Subjective/perceptual assessment: Resonation Screening Test (RST). The Resonation Screening Test (Iamharit $\mathrm{P}$, Chuangsuwanich A, Manochioponig S: Can the surgeon diagnose speech resonation problem by the speech resonation screening test. Paper presented at the 29th scientific conference, Royal College of Surgeons of Thailand, Pattaya, Chonburi, Thailand, July 31, 2004; Table 2), consists of a 5-item assessment for determination of VPI (hypernasality). The RST is composed of 3 short speech sentences and 2 examinations of velopharyngeal function. Each of the 5 items is rated as being either normal (successful) or abnormal (unsuccessful). Normal/successful outcome is given a zero score and abnormal/unsuccessful outcomes are given a score of 1 . The maximum score is 5 , with a score of 0 score indicating normal velopharyngeal function.

Objective/instrument-based assessment: nasometer. A nasometer (6200-3, Kay Elemetrics Corp.) is a computer-based instrument. This device consists of a headset that has directional microphones for the nose and mouth. These microphones are separated by a baffle that rests against the upper lip (Fig. 1). The microphones pick up acoustic energy from the nasal and oral cavities. The ratio of nasal to total (nasal plus oral) acoustic energy is then calculated. The calculated ratio is then multiplied by 100 


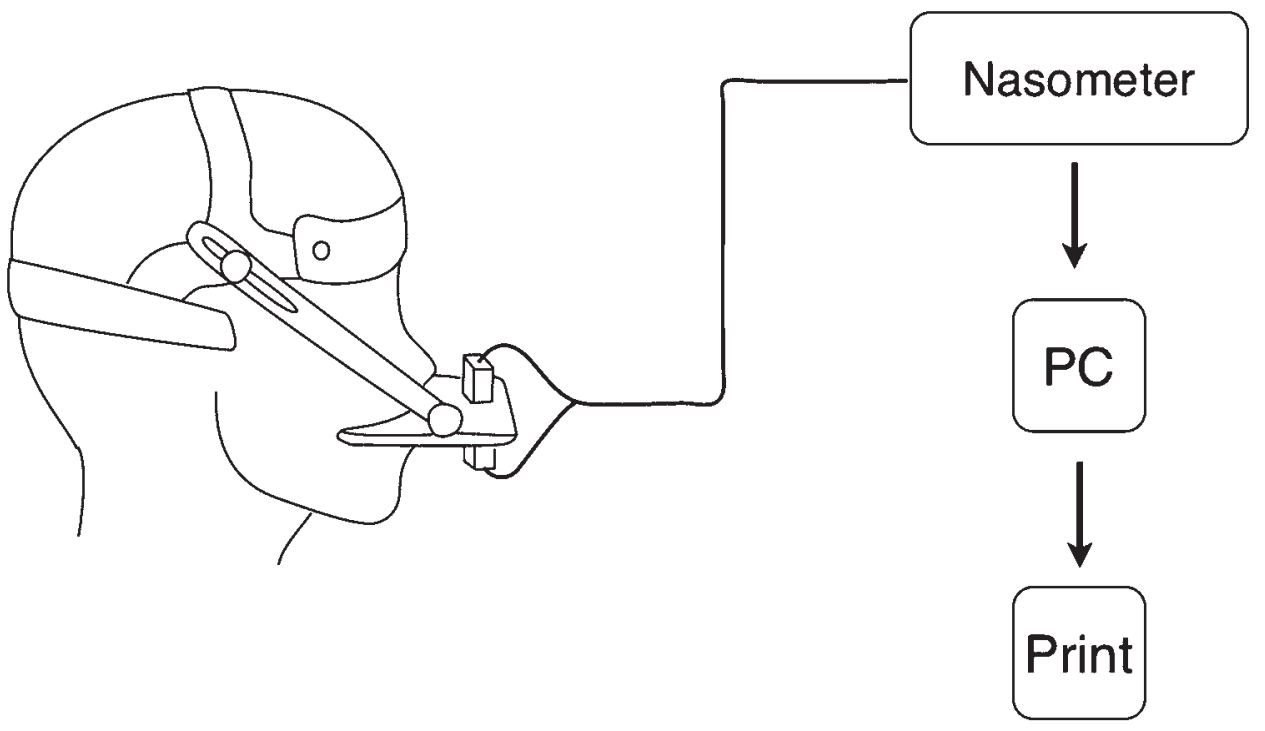

FIG. 1. Illustration of nasometer positioning and flow diagram of processing. $P C=$ personal computer.

and expressed as a "nasalance" score. Individuals with VPI were assumed as having hypernasality, which manifested as high nasalance scores. ${ }^{5,10,18,22,37}$

Patients were asked to read 3 standard passages from the Thai Nasality Test. ${ }^{25}$ The first passage is a nasal passage that is rich in nasal consonants $(\mathrm{m}, \mathrm{n}, \mathrm{ng})$, for which the velopharyngeal valve remains open to allow sound transmission into the nasal cavity. The second passage is an oral passage that is devoid of nasal consonants. The third passage is an oronasal passage that comprises a mix of oral and nasal consonants used in everyday conversation. Nasalance scores were compared with normative data of Thai subjects. ${ }^{25}$ This instrument provides objective information regarding resonance and nasality. In the present study, only the oronasal passage was used to determine whether resonance was hypernasality or not.

\section{Statistical Analysis}

Statistical analyses were performed using PASW Statistics (version 18.0, SPSS, Inc.). Data are presented as number $(\%)$, mean \pm standard deviation (SD), or median and interquartile range (IQR). Comparisons between before and after shunt placement were performed using the Wilcoxon signed ranks test or McNemar's test. Correlations were analyzed using Spearman's rank correlation coefficient $\left(r_{s}\right)$, Pearson's correlation coefficient $(r)$, or point-biserial correlation coefficient $\left(r_{p}\right)$. A p value $<0.05$ was considered statistically significant.

\section{Results}

\section{Characteristics of Patients}

There were 35 males and 18 females, with a mean age of 71.89 years. Of 53 patients who underwent shunt surgery, 3 patients were lost to follow-up at the 6-month time point for the following reasons: 1 patient died due to upper airway obstruction, 1 patient developed pneumonia with sepsis, and 1 patient suffered a traumatic intracranial hematoma (ICH; Fig. 2). Patient demographic data are shown in Table 3.

\section{Clinical Outcomes}

Patient clinical data are given in Table 4. Significant improvement was observed in all triad symptoms (gait, cognition, and urination) after shunt surgery $(\mathrm{p}<0.05$; Table 4). Fifty-two patients improved in at least 1 of 3 triad symptoms. One patient was a nonresponder, having failed to improve in any of the 3 triad symptoms. The nonresponding patient also developed acute kidney injury at 1 month after shunt placement.

\section{Swallowing Assessment}

Fifty patients received swallowing assessment at 6 months postoperatively. Three patients were lost to followup for the reasons described immediately above. Preoperatively, $43 / 50$ patients $(86 \%)$ had swallowing problems. The maximum SPQ score in our study population was 10 points out of a possible maximum of 16 points (Fig. 3). The 5 most frequent symptoms were choking, chronic cough, hoarseness, wet/gurgly voice, and difficulty swallowing, respectively.

Six months postoperatively, $37 / 43$ patients $(86 \%)$ experienced improvement in swallowing. Of the 43 patients with preoperative swallowing deficits, 19 became symptom-free, 18 had decreasing symptoms, 5 had no change, and 1 patient's symptoms worsened ( $p<0.001$; Fig. 3).

A statistically significant correlation was identified between a swallowing problem and gait performance before shunt placement $(r=0.358, p=0.009)$. In addition, a swallowing problem was negatively correlated with TMSE $(\mathrm{r}=$ $-0.394, p=0.005)$ at 6 months after shunting.

\section{Speech Assessment}

Forty-nine patients were given a speech assessment at 6 months after shunt placement. Three patients were lost 


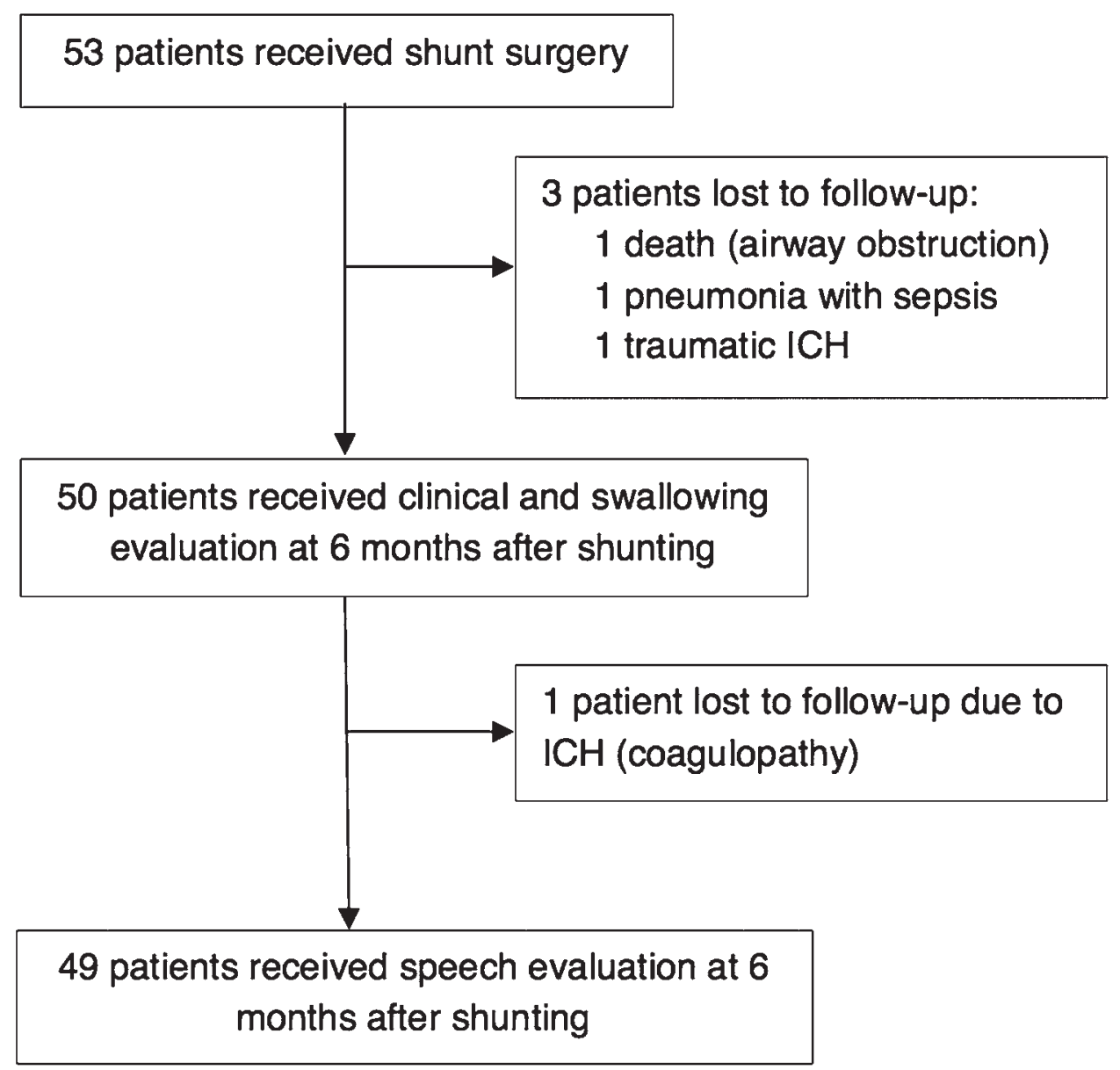

FIG. 2. Flow chart of the trial.

to follow-up for the reasons mentioned above, 1 of whom developed an ICH due to coagulopathy.

\section{Articulation Test}

Preoperatively, 33/49 patients $(67 \%)$ had articulation disorders. The articulation of 28 patients remained abnormal postoperatively (Table 3 ). The main articulation problem was reduction or omission of $/ \mathrm{r} /$ and $/ \mathrm{l} /$ of the cluster sounds. There was no significant difference in articulation between before and after surgery $(\mathrm{p}=0.18)$, but articulation correlated with gait performance prior to shunting $\left(\mathrm{r}_{\mathrm{p}}\right.$ $=0.362, \mathrm{p}=0.008$ ).

\section{Volume and Frequency}

There was significant improvement in voice loudness $(\mathrm{p}=0.009)$, but no significant change in voice frequency (Table 4). No correlation was identified between loudness and triad symptoms.

\section{Resonance}

Resonance Screening Test

Preoperatively, $37 / 49$ patients $(75.51 \%)$ had abnormal RST scores (Fig. 4). Postoperatively, 21/37 patients (56.75\%) had an improved RST score. Of the 37 patients with preoperatively abnormal RST scores, 11 became zero RST scores, 10 had a decreased RST score, 13 had no change, and 3 experienced deterioration in their condition at 6 months after shunt placement. Of the 12 patients with preoperatively normal RST scores, 2 had increased RST scores and 10 remained at a normal RST score at 6 months after shunt placement. There was significant improvement in VPI when comparing preoperative and postoperative RST scores $(p=0.008)$. The RST was found to be negatively correlated with TMSE $(r=-0.502, p<0.001)$ before shunting.

\section{Nasometer}

Mean nasalance scores are shown in Table 4. Preoperatively, $11 / 49$ patients $(22.44 \%)$ had hypernasality. After shunt placement, only 8 patients still had hypernasality ( $p$ $=0.54$ ). No significant difference was observed between preoperative and postoperative mean nasalance scores.

RST score was significantly correlated with both nasalance score $(r=0.302, p=0.028)$ and hypernasality status $\left(r_{p}=0.360, p=0.008\right)$ before shunt placement. In addition, normal resonance was statistically significantly correlated with better cognition (TMSE) before shunt placement $\left(r_{p}=2.240, p=0.025\right)$. 
TABLE 3. Demographic data, clinical characteristics, and duration of symptoms in 53 patients with $\mathrm{NPH}$

\begin{tabular}{lc}
\hline \multicolumn{1}{c}{ Variable } & \multicolumn{1}{c}{ Value } \\
\hline Mean age in yrs (range) & $71.89(49-87)$ \\
\hline Sex (M/F) & $(35 / 18)$ \\
\hline Disease (\%) & $38(71.7)$ \\
\hline Idiopathic NPH & $15(28.3)$ \\
\hline Secondary NPH & \\
\hline Median duration of symptoms in mos (IQR) & $12(6-24)$ \\
\hline Gait & $12(6-42)$ \\
\hline Cognitive & $12(4-24)$ \\
\hline Incontinence & $0.334 \pm 0.03$ \\
\hline Mean Evan ratio \pm SD & $14.22 \pm 4.38$ \\
\hline Mean CSF pressure \pm SD $\left(\mathrm{cm} \mathrm{H}_{2} \mathrm{O}\right)$ & \\
\hline Shunt type (\%) & $30(56.6)$ \\
\hline Programmable VPS & $3(5.7)$ \\
\hline Conventional VPS & $20(37.7)$ \\
\hline Programmable LPS
\end{tabular}

\section{Discussion}

In 1975, Adams remarked that his patients with NPH became quiet and had slow speech that progressively developed into whispering or no ability to speak at all. ${ }^{1}$ To the best of our knowledge, this is the first study to address bulbar dysfunction in NPH. Of 53 probable patients with NPH, only 1 was identified as a nonresponder after shunt placement surgery. Preoperatively, $86 \%$ of patients with NPH had swallowing problems and $75 \%$ had speech deficits due to velopharyngeal inadequacy. After shunt placement, significant improvement was observed in swallowing function, speech characteristic (resonation), and speech quality (increasing volume). Statistically significant correlations were found between swallowing problem and gait disturbance, articulation disorder and gait disturbance, and speech problem and cognitive impairment.

Interestingly, no previous investigation has reported on bulbar dysfunction in NPH, even though dysphagia is a very common feature in neurological disorders. Dysphagia has been reported to affect $22 \%-65 \%$ of patients with acute stroke, $36 \%$ of symptomatic patients with Parkinson's disease, and more than $30 \%$ of patients with multiple sclerosis. ${ }^{3}$ Rosler et al. reported an inverse relationship between Mini-Mental State Examination score and severity of swallowing impairment. ${ }^{41}$ The present study found bulbar dysfunction in patients with NPH to be as high as $86 \%$. We also found bulbar dysfunction to be significantly correlated with TMSE score.

This study had 15 patients with secondary NPH (28\%). One patient was lost to follow-up due to pneumonia with sepsis. The diseases of the patients before NPH consisted of 7 with supratentorial tumor, 3 with supratentorial ICH, 2 with subarachnoid hemorrhage, 1 with traumatic epidural hematoma, and 1 with previous craniectomy. None of the patients had bulbar symptoms when they had these diseases before NPH and they experienced a good recovery after treatment. As such, the comorbid disease of second-
TABLE 4. Clinical parameters and voice assessments before surgery and at 6 months after shunt placement surgery*

\begin{tabular}{|c|c|c|c|}
\hline Variable & Preop & Postop & $p$ Value \\
\hline \multicolumn{4}{|l|}{ Median gait (IQR)† } \\
\hline No. of steps in $10 \mathrm{~m}$ & $33.5(22-56)$ & $29.5(19-47)$ & 0.025 \\
\hline Seconds in $10 \mathrm{~m}$ & $26.5(13-53)$ & $17.6(12-35)$ & 0.035 \\
\hline \multicolumn{4}{|l|}{ Cognitive $†$} \\
\hline Mean TMSE \pm SD & $18 \pm 7$ & $23 \pm 7$ & $<0.001$ \\
\hline \multicolumn{4}{|l|}{ Urinary† } \\
\hline Incontinence (\%) & $46(92)$ & $33(66)$ & $<0.001$ \\
\hline \multicolumn{4}{|l|}{ Voice } \\
\hline $\begin{array}{l}\text { Abnormal articula- } \\
\text { tion (\%) }\end{array}$ & $33(67)$ & $28(57)$ & 0.18 \\
\hline $\begin{array}{l}\text { Mean volume } \pm \text { SD } \\
\quad(\mathrm{dB})\end{array}$ & $69.38 \pm 4.91$ & $71.78 \pm 5.08$ & 0.009 \\
\hline $\begin{array}{l}\text { Mean frequency } \pm \\
\mathrm{SD}(\mathrm{Hz})\end{array}$ & $169.32 \pm 37.46$ & $168.50 \pm 34.00$ & 0.833 \\
\hline \multicolumn{4}{|l|}{$\begin{array}{l}\text { Mean \% nasalance } \\
\text { score } \pm \text { SD }\end{array}$} \\
\hline Oral sound & $24 \pm 14$ & $21 \pm 9$ & 0.146 \\
\hline Oronasal sound & $40 \pm 9$ & $38 \pm 9$ & 0.242 \\
\hline Nasal sound & $54 \pm 12$ & $53 \pm 10$ & 0.379 \\
\hline Hypernasality (\%)‡ & $11(22.44)$ & $8(16.32)$ & 0.54 \\
\hline
\end{tabular}

${ }^{*}$ Boldface type indicates statistical significance.

$\dagger$ In 50 patients.

$\ddagger$ In 49 patients.

ary NPH in the present study should not have caused the bulbar palsy. The patients with neurological lesions that cause bulbar palsy were not enrolled because of the exclusion criteria.

Based on our clinical experience, we observed that severity of bulbar symptoms correlated well with late or worsening NPH triad symptoms, which were usually found in cases with severe apathy or sleepiness. Inadequate drainage after CSF shunting also correlated with worsening of bulbar symptoms. In most cases, bulbar symptoms respond dramatically to both CSF shunting and the CSF tap test. As such, they can be used as landmark symptoms for diagnosis and treatment monitoring.

There are 2 possible pathoanatomical causes of bulbar dysfunction in NPH. The first cause involves PVWM damage. Levine et al. demonstrated that increasing PVWM lesions can affect prolonged oropharyngeal swallowing duration..$^{20}$ Several studies have shown that reduced cerebral blood flow (CBF) in PVWM correlates with the triad symptoms of NPH. ${ }^{15,52}$ Momjian et al. found white matter regional $\mathrm{CBF}$ to be reduced in NPH with an abnormal gradient from the lateral ventricle to the subcortical white matter. ${ }^{32}$ Mechanisms responsible for gait disturbance include reduction of blood flow, reduced metabolism, and altered neuronal conduction due to stretching of the corticospinal tract (CST) ${ }^{9,15,35}$ Using diffusion tensor tractography, Jang and Seo found the corticobulbar tract (CBT) to be anteromedial to the CST at the lateral ventricle level..$^{13}$ The location of the CBT is close to the CST.11,19,21,36 The 


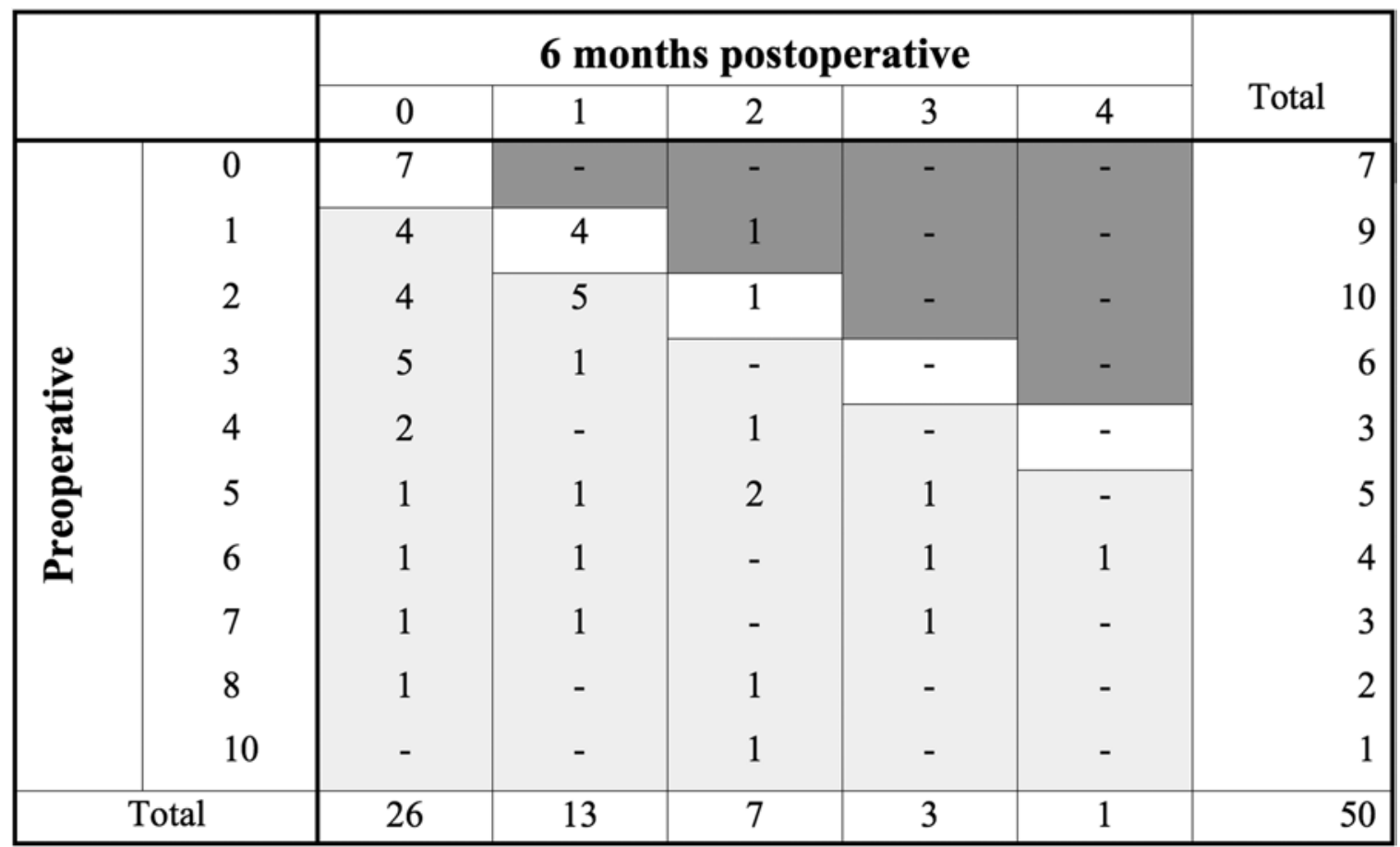

FIG. 3. Distribution of change in swallowing problem severity score from preoperatively to 6 months postoperatively. The numbers in the first row and first column represent the number of symptoms (SPQ score). Clear cells indicate no change, light gray cells indicate improvement, and dark gray cells indicate deterioration.

CBT can be distorted by either or both enlarged ventricles and/or reduced CBF. Moreover, Rogers et al. reported that ventricular dilation causes heterogeneous displacement and deformation on the periventricular fiber tracts. ${ }^{40}$

The second cause is hypoperfusion around the Sylvian fissure region ${ }^{42}$ in NPH, which is the location of the swallowing and laryngeal motor cortex ${ }^{38,44}$ Hypoperfusion at the perisylvian cortex can be explained by dilation of the Sylvian cistern, which is a common finding in idiopathic $\mathrm{NPH} .{ }^{33,50}$
Both impaired CBT and cortical control of bulbar functions may have resulted in swallowing and speech problems in this study. Therefore, increased perfusion in these areas after shunt placement may have resulted in improvement in bulbar dysfunction.

We found significant improvement in VPI after shunt placement according to the RST, but changes in nasometer results did not reach statistical significance. As expected, we found the RST score to be significantly correlated with both nasalance score $(r=0.302, \mathrm{p}=0.028)$ and hyperna-

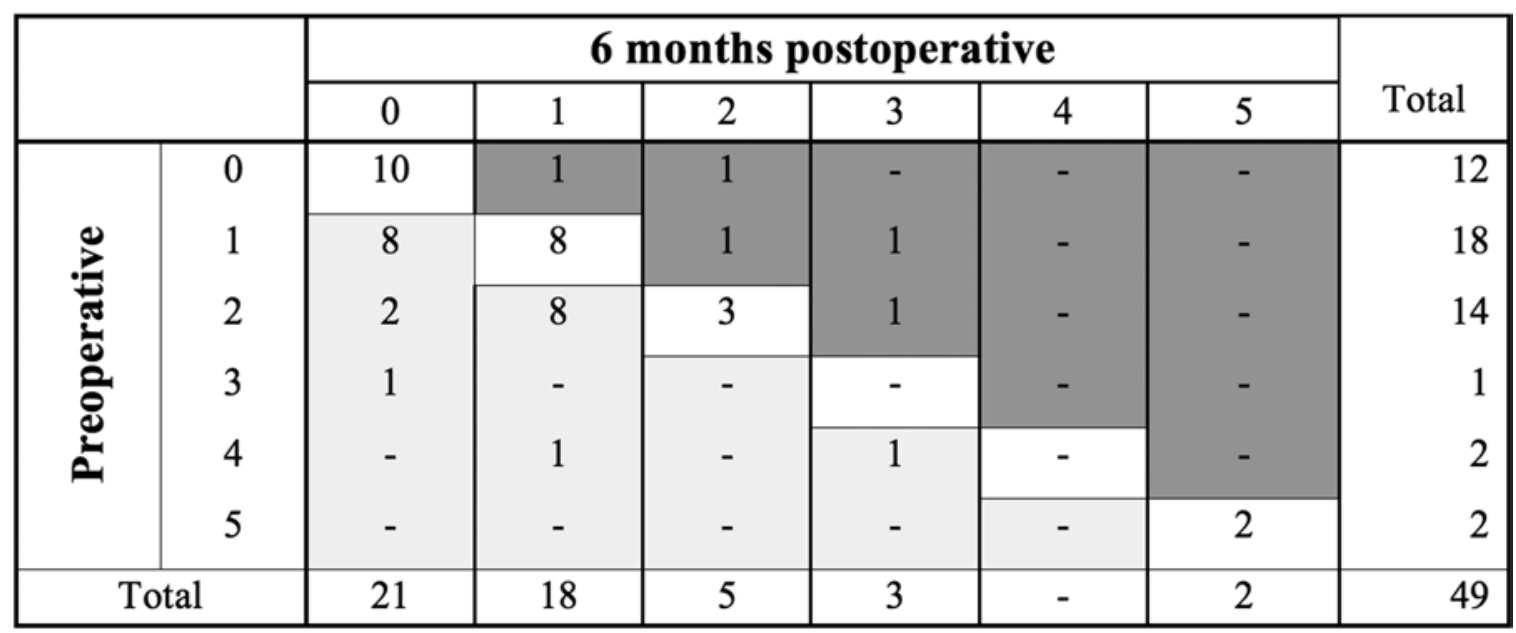

FIG. 4. Distribution of change in RST score from preoperatively to 6 months postoperatively. The numbers in the first row and first column represent the RST score. Clear cells indicate no change, light gray cells indicate improvement, and dark gray cells indicate deterioration. 
sality status $\left(r_{p}=0.360, p=0.008\right)$ before shunt placement. This finding was not surprising, because these two assessment techniques measure the same phenomena and do so in the same way. High nasalance scores were expected among individuals who were judged as having hypernasality, because both the nasometer and the human ear are sensitive to speech in which nonnasal consonants are predicted with increased nasal resonance. Thus, the RST can be used as effectively as auditory perceptual assessment.

Regarding the oronasal nasalance score, which reflects nasality in normal conversation, we found a mean oronasal nasalance score in our patients with NPH of about $40 \%$. This is in agreement with the previous study by Manochiopinig et al., ${ }^{25}$ who reported a mean of $42 \%$ in 36 dysarthric speakers and $39 \%$ in normal speakers. Further comparison of our oronasal nasalance scores with other preexisting normal subject studies were conducted and reviewed. Our NPH nasalance score in this study achieved the highest score among the other normal group scores. For example, Hutchinson et al. reported nasalance scores in older healthy subjects of $23 \%$ for males and $32 \%$ for females. ${ }^{10}$ The other studies in mixed-age groups were IrishEnglish at 26\%, ${ }^{46}$ Flemish at $33.8 \%,{ }^{49}$ Korean at 34\%, and Cantonese at 35.4\%. ${ }^{51}$ The reason that these different languages could be taken into account is that the efficacy of the objective (instrument-based) measurements was based on speech stimulus items. Therefore, differences in nasalance scores among different languages are due to the phonetic characteristics of the test words.

This study has some notable limitations. There are several potential reasons for the finding of no significant change in postoperative nasalance score, the first of which is speaking behavior. Some patients in our study had hyponasality speech for nasal consonants $(/ \mathrm{m}, \mathrm{n}, \mathrm{ng} /)$ or hypernasality speech for oral consonants used in normal conservation. For example, speakers who habitually fail to open their mouths properly/widely may produce hypernasal speech. In another setting, speakers with allergies who have recurrent nasal congestion tend to have denasal/ hyponasal speech. This may cause a false-positive result. Secondly, the nasometer test requires long spoken passages and is time-consuming. Accordingly, patients with poor cognition may lose attention and become uncooperative. Consistent with that assumption, our results showed normal resonance to be significantly correlated with better cognitive scores (TMSE) before shunt placement $\left(\mathrm{r}_{\mathrm{p}}=\right.$ $2.240, p=0.025$ ), whereas RST score was negatively correlated with TMSE $(r=-0.502, p<0.001)$ before shunt placement. This implies that only patients who had good cognition would respond to the nasometer test. It can also be argued that the RST score may be more appropriate than the nasometer in patients with NPH, because the RST takes less time and is easier to conduct/perform. Thirdly, there could also be a potential selection bias in the inclusion criteria in that patients with the worst speech may have been those who might have had the greatest speech improvement after shunt placement, but they were excluded due to not being able to complete the nasometer test.

Regarding the articulation test, we expected the results were not significantly different after shunt placement because of the influence of dialects and speaking behavior.
Speech is a complex sensory-motor task. Speech is, therefore, vulnerable to neurological damage, but the objective measurement of speech is difficult. Our results showed a decreased mean nasalance score after shunting, but the decrease was not statistically significant. Moreover, subjective symptoms and the RST score were also significantly improved, with a significant correlation observed between RST and nasalance score.

Another limitation of this study was the lack of a control group (without NPH), against which we could have compared our findings. Moreover, bulbar dysfunction is commonly observed in the elderly and this must be acknowledged as a potential bias. However, and while this may be a weakness, we do not believe that this factor invalidates our results. These acknowledged weaknesses should be considered and factored into any future studies in bulbar dysfunction in NPH.

As described above, bulbar dysfunction is common in patients with NPH. Unusual presentation of NPH symptoms may hinder early diagnosis and prolong initiation of proper treatment. Bulbar symptoms may appear before triad symptoms, especially in atypical cases or in nonambulatory patients. The present study showed that bulbar symptoms respond well to surgery, similar to the improvements observed in gait disturbance. As such, these symptoms improve both diagnosis and treatment monitoring in nonambulatory patients with NPH.

\section{Conclusions}

This is the first study of bulbar dysfunction in patients with NPH. The results showed that the prevalence of bulbar dysfunction is very high. A correlation between bulbar dysfunction and the classic NPH triad has been documented and published. Bulbar symptoms also significantly improved after surgery. As such, bulbar dysfunction should be regarded as a core symptom that should be considered along with the classic triad in the clinical diagnosis and management of NPH.

\section{Acknowledgments}

We gratefully acknowledge Suthipol Udompunturak for assistance with statistical analysis. This study was supported by the Siriraj Research Fund, Faculty of Medicine Siriraj Hospital, Mahidol University.

\section{References}

1. Adams RD: Recent observations on normal pressure hydrocephalus. Schweiz Arch Neurol Neurochir Psychiatr 116:7-15, 1975

2. Adams RD, Fisher CM, Hakim S, Ojemann RG, Sweet WH: Symptomatic occult hydrocephalus with "normal" cerebrospinal-fluid pressure. A treatable syndrome. N Engl J Med 273:117-126, 1965

3. Bours GJ, Speyer R, Lemmens J, Limburg M, de Wit R: Bedside screening tests vs. videofluoroscopy or fibreoptic endoscopic evaluation of swallowing to detect dysphagia in patients with neurological disorders: systematic review. J Adv Nurs 65:477-493, 2009

4. Chistyakov AV, Hafner H, Sinai A, Kaplan B, Zaaroor M: Motor cortex disinhibition in normal-pressure hydrocephalus. J Neurosurg 116:453-459, 2012 
5. Dalston RM, Neiman GS, Gonzalez-Landa G: Nasometric sensitivity and specificity: a cross-dialect and cross-culture study. Cleft Palate Craniofac J 30:285-291, 1993

6. Eide PK, Sorteberg W: Changes in intracranial pulse pressure amplitudes after shunt implantation and adjustment of shunt valve opening pressure in normal pressure hydrocephalus. Acta Neurochir (Wien) 150:1141-1147, 2008

7. Hellström P, Edsbagge M, Archer T, Tisell M, Tullberg M, Wikkels $\varnothing$ C: The neuropsychology of patients with clinically diagnosed idiopathic normal pressure hydrocephalus. Neurosurgery 61:1219-1228, 2007

8. Hellström P, Klinge P, Tans J, Wikkelsø C: A new scale for assessment of severity and outcome in iNPH. Acta Neurol Scand 126:229-237, 2012

9. Hoza D, Vlasák A, Hořínek D, Sameš M, Alfieri A: DTIMRI biomarkers in the search for normal pressure hydrocephalus aetiology: a review. Neurosurg Rev 38:239-244, 2015

10. Hutchinson JM, Robinson KL, Nerbonne MA: Patterns of nasalance in a sample of normal gerontologic subjects. J Commun Disord 11:469-481, 1978

11. Iwatsubo T, Kuzuhara S, Kanemitsu A, Shimada H, Toyokura Y: Corticofugal projections to the motor nuclei of the brainstem and spinal cord in humans. Neurology 40:309-312, 1990

12. Jacobs L, Conti D, Kinkel WR, Manning EJ: "Normal-pressure" hydrocephalus. Relationship of clinical and radiographic findings to improvement following shunt surgery. JAMA 235:510-512, 1976

13. Jang SH, Seo JP: The anatomical location of the corticobulbar tract at the corona radiata in the human brain: diffusion tensor tractography study. Neurosci Lett 590:80-83, 2015

14. Kanno S, Abe N, Saito M, Takagi M, Nishio Y, Hayashi A, et al: White matter involvement in idiopathic normal pressure hydrocephalus: a voxel-based diffusion tensor imaging study. J Neurol 258:1949-1957, 2011

15. Kim MJ, Seo SW, Lee KM, Kim ST, Lee JI, Nam DH, et al: Differential diagnosis of idiopathic normal pressure hydrocephalus from other dementias using diffusion tensor imaging. AJNR Am J Neuroradiol 32:1496-1503, 2011

16. Klinge $P$, Hellström P, Tans J, Wikkels $\varnothing$ C: One-year outcome in the European multicentre study on iNPH. Acta Neurol Scand 126:145-153, 2012

17. Klinge P, Marmarou A, Bergsneider M, Relkin N, Black PM: Outcome of shunting in idiopathic normal-pressure hydrocephalus and the value of outcome assessment in shunted patients. Neurosurgery 57 (3 Suppl):S40-S52, ii-v, 2005

18. Kummer AW, Lee L: Evaluation and treatment of resonance disorders. Lang Speech Hear Serv Sch 27:271-281, 1996

19. Kuypers HG: Corticobular connexions to the pons and lower brain-stem in man: an anatomical study. Brain 81:364-388, 1958

20. Levine R, Robbins JA, Maser A: Periventricular white matter changes and oropharyngeal swallowing in normal individuals. Dysphagia 7:142-147, 1992

21. Liegeois FJ, Butler J, Morgan AT, Clayden JD, Clark CA: Anatomy and lateralization of the human corticobulbar tracts: an fMRI-guided tractography study. Brain Struct Funct 221:3337-3345, 2016

22. Litzaw LL, Dalston RM: The effect of gender upon nasalance scores among normal adult speakers. J Commun Disord 25:55-64, 1992

23. Logemann JA: Evaluation and Treatment of Swallowing Disorders, ed 2. Austin, TX: Pro-Ed, 1998

24. Lundin F, Ulander M, Svanborg E, Wikkelsø C, Leijon G: How active are patients with idiopathic normal pressure hydrocephalus and does activity improve after shunt surgery? A controlled actigraphic study. Clin Neurol Neurosurg 115:192-196, 2013
25. Manochiopinig S, Hunnangkul S, Udjompunturak S: Applicability of Thai nasality test. Siriraj Hosp Gaz 52:155-163, 2000

26. Manochiopinig S, Pracharitpukdee N, Lertsarunyapong S: [The Articulation Characteristics of Normal Thai Children age 3-10 years Assessing by Using the Thai Articulation Test (TAT).] Siriraj Hosp Gaz 50:763-769, 1998 (Thai)

27. Manochiopinig S, Thubthong N, Kayasith P: Dysarthric speech characteristics of Thai stroke patients. Disabil Rehabil Assist Technol 3:332-338, 2008

28. Marmarou A, Black P, Bergsneider M, Klinge P, Relkin N: Guidelines for management of idiopathic normal pressure hydrocephalus: progress to date. Acta Neurochir Suppl 95:237-240, 2005

29. Marmarou A, Young HF, Aygok GA, Sawauchi S, Tsuji O, Yamamoto T, et al: Diagnosis and management of idiopathic normal-pressure hydrocephalus: a prospective study in 151 patients. J Neurosurg 102:987-997, 2005

30. McGirt MJ, Woodworth G, Coon AL, Thomas G, Williams MA, Rigamonti D: Diagnosis, treatment, and analysis of long-term outcomes in idiopathic normal-pressure hydrocephalus. Neurosurgery 57:699-705, 2005

31. Missori $\mathrm{P}$, Scollato A, Formisano R, Currà A, Mina C, Marianetti M, et al: Restoration of sexual activity in patients with chronic hydrocephalus after shunt placement. Acta Neurochir (Wien) 151:1241-1244, 2009

32. Momjian S, Owler BK, Czosnyka Z, Czosnyka M, Pena A, Pickard JD: Pattern of white matter regional cerebral blood flow and autoregulation in normal pressure hydrocephalus. Brain 127:965-972, 2004

33. Mori E, Ishikawa M, Kato T, Kazui H, Miyake H, Miyajima M, et al: Guidelines for management of idiopathic normal pressure hydrocephalus: second edition. Neurol Med Chir (Tokyo) 52:775-809, 2012

34. Oliveira MF, Oliveira JR, Rotta JM, Pinto FC: Psychiatric symptoms are present in most of the patients with idiopathic normal pressure hydrocephalus. Arq Neuropsiquiatr 72:435-438, 2014

35. Osuka S, Matsushita A, Yamamoto T, Saotome K, Isobe T, Nagatomo Y, et al: Evaluation of ventriculomegaly using diffusion tensor imaging: correlations with chronic hydrocephalus and atrophy. J Neurosurg 112:832-839, 2010

36. Pan C, Peck KK, Young RJ, Holodny AI: Somatotopic organization of motor pathways in the internal capsule: a probabilistic diffusion tractography study. AJNR Am J Neuroradiol 33:1274-1280, 2012

37. Park M, Baek WS, Lee E, Koh KS, Kim BK, Baek R: Nasalance scores for normal Korean-speaking adults and children. J Plast Reconstr Aesthet Surg 67:173-177, 2014

38. Penfield W, Boldrey E: Somatic motor and sensory representation in the cerebral cortex of man as studied by electrical stimulation. Brain 60:389-443, 1937

39. Pinner G, Johnson H, Bouman WP, Isaacs J: Psychiatric manifestations of normal-pressure hydrocephalus: a short review and unusual case. Int Psychogeriatr 9:465-470, 1997

40. Rogers A, Bichsel D, Momjian S: Deformation of the corona radiata and internal capsule in normal pressure hydrocephalus. Neurochirurgie 60:216-221, 2014

41. Rösler A, Pfeil S, Lessmann H, Höder J, Befahr A, von Renteln-Kruse W: Dysphagia in dementia: influence of dementia severity and food texture on the prevalence of aspiration and latency to swallow in hospitalized geriatric patients. J Am Med Dir Assoc 16:697-701, 2015

42. Sasaki H, Ishii K, Kono AK, Miyamoto N, Fukuda T, Shimada $\mathrm{K}$, et al: Cerebral perfusion pattern of idiopathic normal pressure hydrocephalus studied by SPECT and statistical brain mapping. Ann Nucl Med 21:39-45, 2007

43. Savolainen S, Paljärvi L, Vapalahti M: Prevalence of Alzheimer's disease in patients investigated for presumed nor- 
mal pressure hydrocephalus: a clinical and neuropathological study. Acta Neurochir (Wien) 141:849-853, 1999

44. Simonyan K: The laryngeal motor cortex: its organization and connectivity. Curr Opin Neurobiol 28:15-21, 2014

45. Stolze H, Kuhtz-Buschbeck JP, Drücke H, Jöhnk K, Diercks $\mathrm{C}$, Palmié S, et al: Gait analysis in idiopathic normal pressure hydrocephalus - which parameters respond to the CSF tap test? Clin Neurophysiol 111:1678-1686, 2000

46. Sweeney T, Sell D, O'Regan M: Nasalance scores for normalspeaking Irish children. Cleft Palate Craniofac J 41:168174,2004

47. Toma AK, Stapleton S, Papadopoulos MC, Kitchen ND, Watkins LD: Natural history of idiopathic normal-pressure hydrocephalus. Neurosurg Rev 34:433-439, 2011

48. Train The Brain Forum Committee: [Thai Mental State Examination (TMSE).] Siriraj Hosp Gaz 45:359-374, 1993 (Thai)

49. Van Lierde KM, Wuyts FL, De Bodt M, Van Cauwenberge P: Nasometric values for normal nasal resonance in the speech of young Flemish adults. Cleft Palate Craniofac J 38:112118,2001

50. Virhammar J, Laurell K, Cesarini KG, Larsson EM: Preoperative prognostic value of MRI findings in 108 patients with idiopathic normal pressure hydrocephalus. AJNR Am J Neuroradiol 35:2311-2318, 2014

51. Whitehill TL: Nasalance measures in Cantonese-speaking women. Cleft Palate Craniofac J 38:119-125, 2001

52. Ziegelitz D, Arvidsson J, Hellström P, Tullberg M, Wikkels $\varnothing$ C, Starck G: In patients with idiopathic normal pressure hydrocephalus postoperative cerebral perfusion changes measured by dynamic susceptibility contrast magnetic resonance imaging correlate with clinical improvement. J Comput Assist Tomogr 39:531-540, 2015

\section{Disclosures}

The authors report no conflict of interest concerning the materials or methods used in this study or the findings specified in this paper.

\section{Author Contributions}

Conception and design: all authors. Acquisition of data: all authors. Analysis and interpretation of data: all authors. Drafting the article: all authors. Critically revising the article: Benjamin, Chankaew, Srirabheebhat, Manochiopinig. Reviewed submitted version of manuscript: Benjamin, Chankaew, Srirabheebhat, Manochiopinig. Statistical analysis: Benjamin, Chankaew, Manochiopinig. Administrative/technical/material support: Chankaew, Manochiopinig, Witthiwej. Study supervision: Chankaew, Srirabheebhat.

\section{Correspondence}

Itsara Benjamin, Division of Neurosurgery, Department of Surgery, Faculty of Medicine Siriraj Hospital, Mahidol University, 2 Prannok Rd., Bangkoknoi, Bangkok 10700, Thailand. email: oak_safehouse@hotmail.com. 